\title{
COMERCIALIZAÇÃO DE CAJU IN NATURA NA REGIÃO NOROESTE DO ESTADO DE SÃO PAULO ${ }^{1}$
}

\author{
RICARDO ALESSANDRO PETINARI², MARIA APARECIDA ANSELMO TARSITANO ${ }^{3}$
}

\begin{abstract}
RESUMO:. Para estimar e analisar os custos de comercialização e identificar locais e formas de comercialização do caju, foram realizadas, durante o ano de 2000/01, entrevistas com produtores, técnicos da extensão rural, agentes intermediários e pesquisadores de órgãos públicos. Também foram levantadas informações na Companhia de Entrepostos e Armazéns Gerais de São Paulo (CEAGESP). Os custos agregados pelo segmento da comercialização devem-se, em grande parte, às despesas com o transporte até os grandes centros atacadistas, e também à comissão definida pelo atacadista. Para o produtor da região Noroeste do Estado de São Paulo, o ideal seria direcionar sua produção para os meses de janeiro a junho, garantindo assim melhores preços e com isso resultados mais satisfatórios.
\end{abstract}

Termos para indexação: caju-anão, produção, comercialização.

\section{CASHEW (Anacardium occidentale L.) COMMERCIALIZATION IN NORTHWEST OF SÃO PAULO STATE}

ABSTRACT: Intending to estimate and analyze the commercialization costs and identify places and forms of the cashew commercialization it was accomplished, during the year of 2000/01, interviews with farmers, technicians of agronomic assistance, intermediate agents and professionals of public research agencies. Also information were obtained within the General Warehouses Company of São Paulo State (CEAGESP). The aggregate costs to the cashew by the commercialization segment, derives, in large extent, to the carrier costs until the great wholesale centers, and also to the commission imposed by the wholesaler. For the farmers of the northwest region of São Paulo State, the correct would be to direct their production to the months of January and June, thus guaranteeing higher prices and more satisfactory results.

Index terms: dwarfed cashew, production, commercialization

\section{INTRODUÇÃO}

O cajueiro é cultura de grande importância econômica, tanto pelo fato de ser consumida in natura como pela industrialização de seus frutos, resultando em sucos e outros produtos bastante consumidos nos mercados interno e externo. Atualmente é cultivado em diversos países, destacando-se pela produção Índia, Brasil, Moçambique e Tanzânia (Nehmi et al, 1998).

No Brasil, os Estados do Ceará, Piauí e Rio Grande do Norte produziram em 2000, aproximadamente, 166 mil toneladas de castanha de caju (100\% da produção nacional) em uma área de 597 mil hectares. Em 1999, o Brasil exportou mais de 24 mil toneladas de castanha de caju, no valor aproximado de US\$ 142 milhões. Os Estados Unidos consomem 60 $\%$ de toda a castanha de caju negociada no comércio mundial, e o Brasil, por sua vez, coloca nesse país cerca de $25 \%$ de sua produção exportável (Nehmi et al, 2000).

A produtividade do cajueiro é expressiva na região Nordeste do Brasil, onde a EMBRAPA, através do Centro Nacional de Pesquisa em Agroindústria Tropical (CNPAT) localizada em Pacajus-CE, vem desenvolvendo várias pesquisas. A novidade é a variedade "anão-precoce" que deverá, ao longo do tempo, substituir o caju comum, que apresenta baixa produtividade e dificuldades na colheita, devido à multiplicação por sementes, à polinização cruzada, ao manejo inadequado da cultura e também por serem muito altos, podendo chegar a até 14 metros.

Além da EMBRAPA, algumas empresas do Nordeste também estão investindo em pesquisas para melhorar a produção de caju desta região, com o objetivo de direcionar a produção para a comercialização in natura. Atualmente, a produção vem para a região Sudeste, em caminhões-frigorífico, que fazem o percurso de mais de três mil quilômetros em três dias. A venda in natura reverte a tradição apontada nas estimativas oficiais de desperdício de mais de $95 \%$ da safra de pedúnculo do caju, em detrimento da castanha, que a indústria de suco não pode aproveitar (Araripe, 2000).

Com a difusão desta variedade ("anão precoce") outros Estados vêm interessando-se pela cultura, como Mato Grosso do Sul e São Paulo. Na região Noroeste do Estado de São Paulo, a empresa ASADA - Empreendimentos Agroindustrial- localizada no município de
Mirandópolis, introduziu a cultura do cajueiro em 1994, quando trouxe o primeiro lote de mudas enxertadas produzidas no Ceará. O projeto CAJUNOR, denominação da ASADA para seu empreendimento com caju, tinha por objetivo implantar, até o ano 2003, mais de 1 milhão de pés de cajueiro-anão-precoce (em uma área aproximada de 2000 alqueires), estimativa esta que deverá ser alcançada somente em 2007. Nesse empreendimento, estão incluídos desde a produção de mudas até a instalação de indústrias para processamento da castanha, do caju em passas, sucos e ração.

Com relação à cultura do cajueiro no Estado de São Paulo, são poucos os resultados de pesquisa colocados à disposição dos agricultores, no que diz respeito à produtividade, comercialização e aos aspectos ligados à economicidade, como custo de produção e análise de investimentos. Esses indicadores são importantes subsídios na tomada de decisão pelos agricultores no planejamento da produção.

O objetivo geral do presente trabalho foi descrever e caracterizar a produção e o mercado interno da cultura do caju. São objetivos específicos: a) estimar os custos de comercialização; b) analisar o comportamento de mercado da fruta; e c) verificar a produção e a procedência em diferentes mercados.

\section{MATERIALEMÉTODOS}

A região de Mirandópolis, pertencente ao EDR de Andradina, destaca-se na produção de frutas, principalmente com goiaba, abacaxi e manga. Segundo dados apresentados por Mereti (2001), Mirandópolis apresenta o melhor desempenho na geração de renda, quando comparado com outros municípios desta região. A explicação está na composição da produção, o valor agregado pela exploração frutífera, com destaque para a produção de goiaba que, em 1999, apresentou o maior valor $\mathrm{R} \$ 7.681 .000,00$, representando quase $26 \%$ do valor total das explorações em Mirandópolis. Nos últimos dois anos, os produtores, desestimulados com os preços recebidos pela indústria, estão abandonando e/ou erradicando a cultura da goiaba na região, e apostando em outras frutíferas, como, por exemplo, na cultura do cajueiro.

Segundo ASADA Empreendimentos Agroindustrial ${ }^{1}$ (2002), a cultura do cajueiro-anão-precoce vem expandindo-se pela região Noro-

${ }^{1}$ Comunicação pessoal.

1 (Trabalho 015/2002). Recebido: 22/02/2002. Aceito para publicação: 06/09/2002.

2 Eng ${ }^{\circ}$. Agr ${ }^{\circ}$. Mestrando em Agronomia FE / UNESP - Ilha Solteira - SP, Bolsista FAPESP, E-mail: pctinari@ agr.fcis.unesp.br. Rua oito, nº 2875, centro, CEP 15.700000 , Jales-SP.

3 Prof $^{\mathrm{a}}$ Dr $^{\mathrm{a}}$ do Departamento de Fitotecnia, Tecnologia de Alimentos e Sócio-Economia da FE/UNESP, Av. Brasil Centro, nº 56, Caixa Postal 31, CEP 15.385-000, Ilha Solteira-SP.E-mail: maat@agr.feis.unesp.br. 
este do Estado de São Paulo, onde o EDR de Andradina se destaca em termos de pés novos, com 14.377. Isto pode ser explicado pelo fato de o município de Mirandópolis fazer parte deste EDR, local onde foi introduzida a cultura pela empresa ASADA Empreendimentos Agroindustrial

Para estimar e analisar os custos de comercialização, foram realizadas entrevistas com produtores, técnicos da extensão rural, agentes intermediários e pesquisadores de órgãos públicos. Também foram levantadas informações na Companhia de Entrepostos e Armazéns Gerais de São Paulo (CEAGESP).

O levantamento dos dados necessários à realização do trabalho, nos aspectos ligados à tecnologia, produção e preços, foi efetuado junto a dois produtores rurais do município de Mirandópolis, onde a cultura já se encontra em produção. Esses produtores podem ser considerados representativos dessa atividade na região por adotarem bom nível tecnológico e obterem produtividade e qualidade da fruta. Os custos de comercialização foram estimados até o centro atacadista do Entreposto Terminal do Jaguaré em São Paulo, não abrangendo, portanto, os segmentos pós-atacado da cadeia de comercialização, considerado o mercado mais significativo do Brasil, com grande movimentação comercial dos produtos hortifrutícolas brasileiros.

\section{RESULTADOSE DISCUSSÃO}

\section{A comercialização e seus custos}

As formas mais praticadas de comercialização da fruta na região Noroeste de São Paulo são a de preço em consignação e a de preço combinado, feitas com atacadistas diretamente na propriedade rural. A forma predominante é a do preço em consignação, em que o produto é enviado para empresas (atacadistas) localizadas nas CEASAs ou CEAGESP-SP, e que são responsáveis pela sua comercialização, repassando aos produtores como preço líquido o preço de venda recebido pela fruta, descontadas as despesas envolvidas. Nesse tipo de venda, o agricultor envia seu produto sem saber o preço que irá receber.

Outro tipo de comercialização, ainda pouco praticado na cultura do caju, é a venda através do preço combinado. Neste sistema, os produtores recebem a visita em sua propriedade de profissionais que trabalham com compra e venda de produtos, com os quais negociam o valor de venda da fruta, que é repassado ao produtor, geralmente após 30 dias.

O caju produzido nesta região pode ser destinado a: venda direta a atacadistas, atuando na CEAGESP (a maioria) ou em outras CEASAs venda direta na porteira para intermediários; venda direta para representantes de indústrias para produção de sucos e doces; ou, ainda, a venda direta a feirantes, supermercados e quitandas da região.

O caju in natura é comercializado em pequenas caixetas de papelão, com 4 bandejas de PVC, com capacidade média para $1,5 \mathrm{~kg}$ (Figuras 02 e 03). Depois, esta caixeta é revestida com filme plástico treta-pak, possibilitando uma maior conservação da fruta.

O transporte é feito por transportadoras da região de Mirandópolis-SP, até a cidade de São Paulo, e em função da distância do local de produção, neste caso de $600 \mathrm{~km}$, o valor do frete é de $\mathrm{R} \$ 0,55 / \mathrm{cx}$ ou US $\$ 0.27 / \mathrm{cx}^{2}$ por caixa. Geralmente, estas transportadoras levam até o Entreposto Terminal da CEAGESP, em São Paulo, vários outros produtos além do caju. Com isto, o preço da caixa a ser transportada é sempre o mesmo, independentemente da quantidade.

Para o descarregamento, é cobrado um valor de $\mathrm{R} \$ 0,10 /$ caixa ou US\$0.05/caixa. A comissão do atacadista é de 17,50\% sobre o preço médio da caixa de caju no atacado, e as despesas com a Seguridade Social $(2,2 \%)$ estão embutidas no valor da comissão.

Os custos de comercialização pela venda em consignação da caixa de caju de $1,5 \mathrm{~kg}$, pelos produtores da região de Mirandópolis-SP, em outubro de 2001, foi de R \$1,53/caixa. Desse valor, $58 \%$ referem-se às despesas com comissão, $36 \%$ com frete e $6 \%$ com custo de descarga.
Dessa forma, o produtor recebe pela caixa de caju R $\$ 3,50 /$ caixa (US $\$ 1.70$ ), que é obtido, descontando-se os custos de frete, descarga e comissão do atacadista, do preço médio da caixa de caju no atacado. Deve-se ressaltar que o produtor é responsável por todas as despesas de produção, colheita, seleção e embalagem.

Considerando o custo total de produção obtido por Petinari (2002), verifica-se que os custos de comercialização representam cerca de $76 \%$ do custo total, valor este considerado elevado pelos produtores.

\section{Comportamento de mercado}

Para a análise do comportamento de mercado do cajueiro, foram levantados dados referentes às quantidades e preços do $\mathrm{kg}$ de caju in natura comercializadas na CEAGESP de São Paulo, referentes ao período de 1992 a 2000.

Verifica-se que, de janeiro até a primeira quinzena de junho, as quantidades de caju (pseudofrutos) comercializadas na CEAGESP são menores, em virtude de corresponder ao período de entressafra nas grandes regiões produtoras do Nordeste do Brasil. A partir da segunda quinzena de junho, observa-se um aumento no volume comercializado, que tende a diminuir no final do ano.

Os preços recebidos pelos produtores rurais da região Noroeste do Estado de São Paulo são referentes à comercialização do caju in natura na CEAGESP de São Paulo, durante a safra 2000-01.

Observa-se claramente que os maiores preços ocorrem de janeiro até a primeira quinzena de julho, correspondendo à época de menor quantidade de frutos. Em janeiro, março, abril e maio, ocorre um grande aumento de preços, pelo fato de haver menor quantidade de frutos ofertados no mercado atacadista de São Paulo.

Atualmente, a utilização da irrigação vem permitindo a colheita por um período maior, cerca de 8 meses no ano, que, aliada a estudos de poda, poderá direcionar toda produção para o primeiro semestre, alcançando melhores preços.

\section{Procedência e destino da produção}

Com a finalidade de determinar-se a procedência e o destino do caju in natura comercializado na CEAGESP, no ano de 2000, foram levantadas as regiões de procedência, suas quantidades e também a porcentagem com que cada região participa no volume comercializado na CEAGESP.

A maior parte da fruta do caju comercializada na CEAGESP, em engradados com capacidade para 3,0 kg, é originária do Estado do Piauí, com cerca de $75.313 \mathrm{~kg}$ (63\%), seguido pelo Rio Grande do Norte (22\%), do total comercializado ${ }^{3}$. O Estado de São Paulo aparece em terceiro lugar, com destaque para a região de Bauru, que é a principal produtora, porém outras áreas dentro do Estado vêm aumentando a produção, como é o caso da região Noroeste.

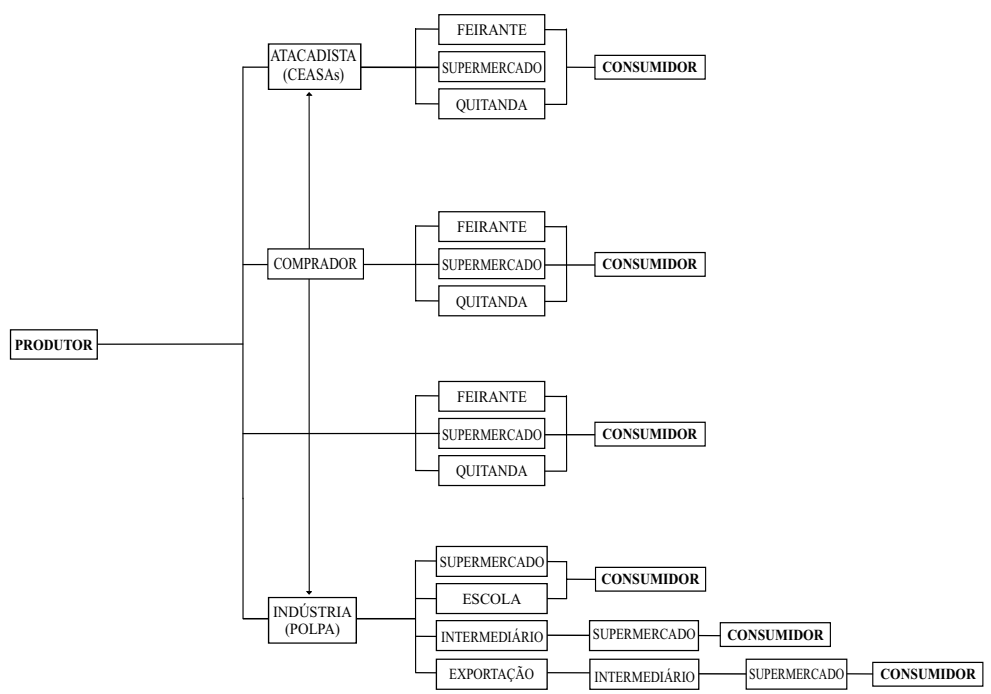

FIGURA 1 - Fluxograma da cadeia de comercialização do caju, na região Noroeste do Estado de São Paulo. 

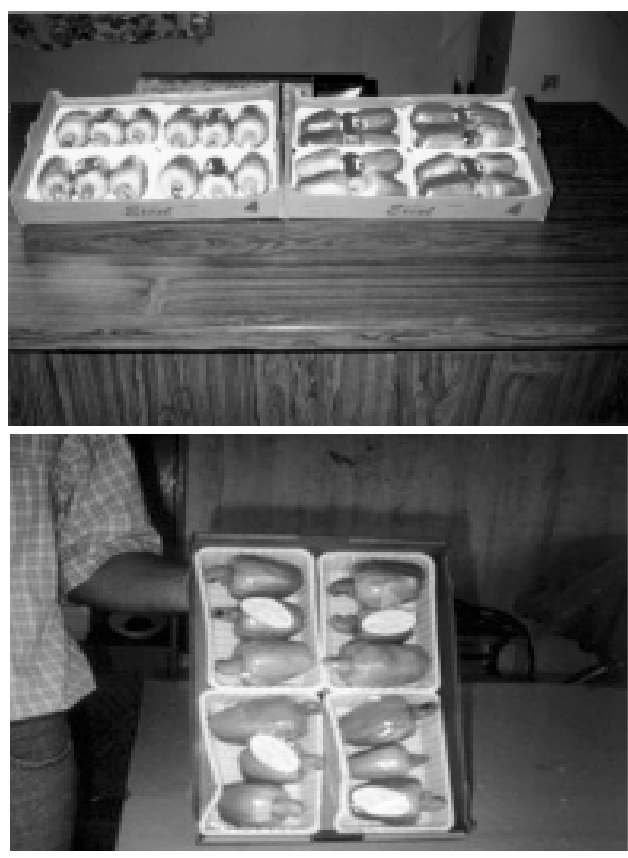

FIGURAS 2 e 3 - Embalagens utilizadas para a comercialização do caju in natura.

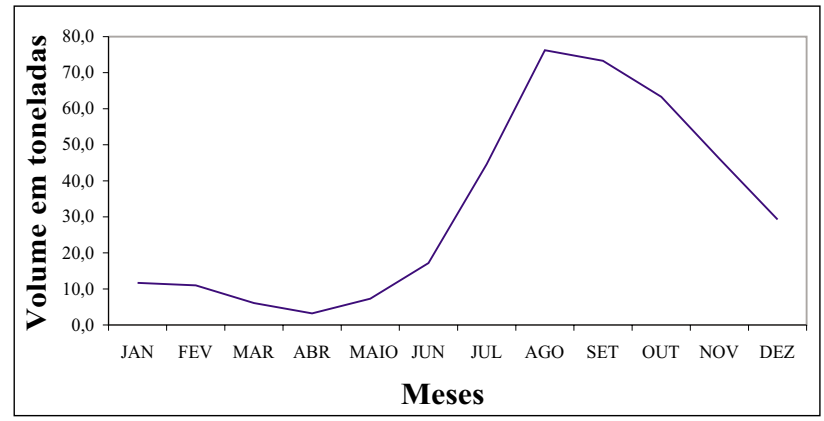

FIGURA 4 - Sazonalidade da oferta de caju na CEAGESP de São Paulo, média de 1992 a 2000.

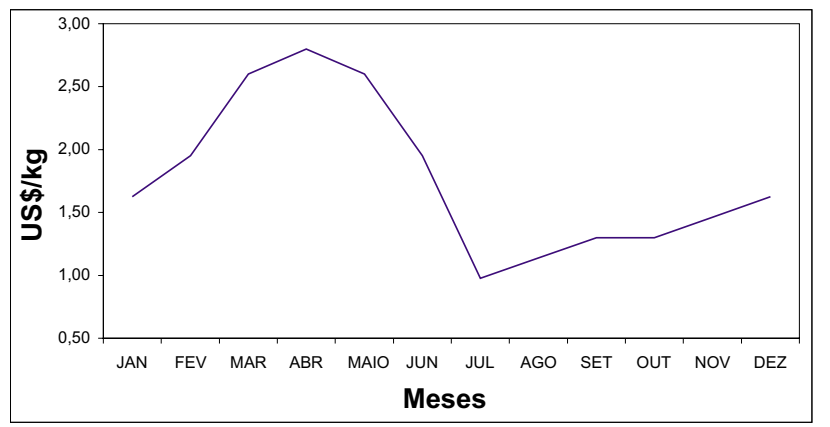

FIGURA 5 - Preços de caju in natura recebidos mensalmente pelos produtores rurais da região Noroeste do Estado de São Paulo, safra 2000-01.
TABELA 1 - Custos envolvendo a comercialização da caixa de caju de $1,5 \mathrm{~kg}$ em Mirandópolis-SP, através da venda pelo preço consignado, outubro de 2001.

\begin{tabular}{|c|c|c|}
\hline \multicolumn{3}{|c|}{ Custos de Comercialização } \\
\hline \multicolumn{3}{|c|}{ 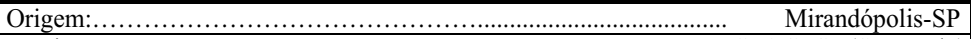 } \\
\hline \multicolumn{3}{|c|}{ 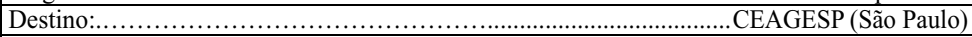 } \\
\hline \multicolumn{3}{|c|}{ Embalagem:.................................................................................. caixa de $1,5 \mathrm{~kg}$} \\
\hline & $\mathbf{R} \$ / \mathbf{c x}$ & US\$/cx \\
\hline Preço me & 5,0 & 2.45 \\
\hline (-) Transporte.. & $\mathbf{0 , 5 5}$ & 0.27 \\
\hline (-) Descarregamento & $\mathbf{0 , 1 0}$ & 0.05 \\
\hline (-) Comissão Atacadista $(17,5 \%) \ldots \ldots \ldots \ldots \ldots$ & $\mathbf{0 , 8 8}$ & 0.43 \\
\hline Preço pago ao produtor............................... & $\mathbf{3 , 5 0}$ & 3,20 \\
\hline
\end{tabular}

Em termos gerais, os destinos são os mais variados possíveis, com destaque para as feiras livres, CEASAs regionais, supermercados e sacolões, que comercializam, respectivamente, $29 \%, 19 \%, 17 \%$ e $13 \%$ do total comercializado na CEAGESP.

\section{CONCLUSÕES}

1 - Os custos incidentes na comercialização do caju na CEAGESP são altos, muito embora representem hoje a única forma de comercialização da fruta in natura.

2 - Em função da predominância da comercialização pelo sistema de preço consignado, fica evidente ao produtor que o ideal seria buscar caminhos alternativos visando a reduzir principalmente os custos com a comissão do atacadista, o que não é fácil.

3 - O início da operação de uma indústria na região que pretende processar a castanha e o pedúnculo do caju, deverá aumentar a competitividade pela fruta.

4 - Para o produtor da região Noroeste do Estado de São Paulo, o ideal seria direcionar sua produção para os meses de janeiro a junho, garantindo assim melhores preços.

\section{REFERÊNCIASBIBLIOGRÁFICAS}

ARARIPE, F. Itaueira expande negócios do caju. Disponível em: <http// :www.gazetamercantilce.com.br/jornal/1168.htm>. Acesso em:11 nov. 2000.

MERETI, O.A.B. Composição da produção agropecuária e renda na microrregião de Andradina nos anos noventa. 2001. 69f. Monografia (Trabalho de Graduação em Agronomia) - Faculdade de Engenharia de Ilha Solteira, Universidade Estadual Paulista, Ilha Solteira, 2001

AGRIANUAL 99: anuário Estatístico da agricultura brasileira. São Paulo: FNP Consultoria \& Comércio. 1998. p.463-7.

AGRIANUAL 2001: Anuário Estatístico da agricultura brasileira. São Paulo: FNP Consultoria \& Comércio, 2000. p.246-7.

PETINARI, R.A. Análise técnica e econômica do cajueiro-anão (Anacardium occidentale $\mathrm{L}$.) na região noroeste do estado de São Paulo. 2002. 103f. Dissertação-(Mestrado). Faculdade de Engenharia de Ilha Solteira, Universidade Estadual Paulista, 2002 